\title{
FORMAÇÃO CONTINUADA DE PROFESSORES E INTERCULTURALIDADE: REFLEXÕES SOBRE ASPECTOS MULTIÉTNICOS DO ENSINO EM LÍNGUA PORTUGUESA
}

\author{
Carmem Véra NUNES SPOTTI ${ }^{\mathrm{i}}$ \\ Maria Rejane Lima BRANDIM ${ }^{\mathrm{ii}}$
}

\begin{abstract}
RESUMO
Os aspectos multiétnicos e multilinguísticos presentes nas salas de aula tornam o ensino e a aprendizagem dos diversos conteúdos curriculares um desafio pedagógico para os professores do Estado de Roraima. A partir de uma pesquisa bibliográfica, cujas principais referências são Weissmann (2018), Feldmann (2009), Moreira e Candau (2007), Candau (2000), Perez Gómez (2000), MacLaren (1997), identificamos que as características das escolas de Roraima são um lócus importantíssimo para o reconhecimento do impacto da diversidade cultural e linguística no trabalho dos professores e que a formação inicial desse profissional não é suficiente para que ele possa dar conta desse desafio. Este artigo visa o debate sobre a formação continuada de professores na perspectiva da interculturalidade, que é essencial para que eles possam identificar, reconhecer e trabalhar com a diversidade presente em suas salas de aula.
\end{abstract}

PALAVRAS-CHAVE: Diversidade linguística; Formação continuada; Interculturalidade.

\section{CONTINUING EDUCATION OF TEACHERS AND INTERCULTURALITY: CONSIDERATIONS OVER MULTIETHNIC ASPECTS OF TEACHING IN PORTUGUESE}

\begin{abstract}
The multiethnic and multilinguistic aspects present in classrooms make the teaching and the learning of many curricular contents a pedagogical challenge to teachers of the State of Roraima. Starting with a bibliographic research whose main references are: Weissmann (2018), Feldmann (2009), Moreira e Candau (2007), Candau (2000), Perez Gómez (2000) and MacLaren (1997), we identified that the characteristics of the schools of Roraima are an important locus to the acknowledgement of the impact of cultural and linguistic diversity on the pedagogical job of teachers, and that professional initial training is not enough so that they can cope with the challenge. This article aims to debate the teachers continuing education under the perspective of interculturality, knowing that it is vital so teachers can identify, acknowledge and work with the diversity present on classrooms.
\end{abstract}

KEYWORDS: Linguistic diversity; Continuing education; Interculturality.

\footnotetext{
i Doutorado em Educação: Currículo pela Pontifícia Universidade Católica de São Paulo. Professora da Universidade Estadual de Roraima e do Centro de Formação. E-mail: carmemspotti@ bol.com.br.

ii Doutorado em Educação: Currículo pela Pontifícia Universidade Católica de São Paulo. Professora do Curso de Licenciatura em Ciências Biológicas do Campus de Parnaíba da Universidade Federal do Delta do Parnaíba. Email: rejanebrandim@ufpi.edu.br.
} 


\section{EDUCACIÓN CONTINUA DE PROFESORES E INTERCULTURALIDAD: REFLEXIONES SOBRE LOS ASPECTOS MULTIÉTNICOS DE LA ENSEÑANZA EN PORTUGUÉS}

\section{RESUMEN}

Los aspectos multiétnicos y multilingüísticos presentes en las aulas hacen de la enseñanza y el aprendizaje de los distintos contenidos curriculares un reto pedagógico para los profesores del Estado de Roraima. Basado en una investigación bibliográfica cuyas principales referencias son: Weissmann (2018), Feldmann (2009), Moreira y Candau (2007), Candau (2000), Pérez Gómez (2000), MacLaren (1997), identificamos que las características de las escuelas de Roraima son un lugar importante para el reconocimiento del impacto de la diversidad cultural y lingüística en el trabajo de los profesores y que la formación inicial de este profesional no es suficiente para que pueda afrontar este reto. Este artículo tiene como objetivo el debate sobre la educación continua de los profesores desde la perspectiva de la interculturalidad, que es esencial para que identifiquen, reconozcan y trabajen con la diversidad presente en sus aulas.

PALABRAS CLAVE: Diversidad lingüística; Educación continua; Interculturalidad.

\section{INTRODUÇÃO}

Quando pensamos em ensino e aprendizagem, preocupamo-nos com o que vamos ensinar e como os alunos vão aprender, mas nem sempre essa preocupação considera a questão da comunicação e seus aspectos multiculturais existentes em nossas escolas. O Brasil é um país com uma vasta extensão territorial, rico cultural e linguisticamente, haja vista que temos regiões com situações "peculiares de línguas de imigração, que são faladas por determinados grupos de pessoas em determinadas comunidades no seu dia a dia" (SPINASSÉ, 2006, p.1). Portanto, apresentamos uma reflexão sobre a interculturalidade existente nas escolas da região Norte do País e que deve permear a formação continuada dos professores que atuam na rede básica de educação, tendo a língua portuguesa como referência linguística, seja em escolas não indígenas, escolas indígenas e/ou escolas que atendam alunos de nacionalidades e/ou línguas diferentes.

Escolhemos como lócus deste trabalho o Estado de Roraima, localizado na região Norte do Brasil, e uma de suas características é o fato de ser uma tríplice fronteira. Limita-se ao Norte e Nordeste com a República Bolivariana da Venezuela, ao Leste com a República Cooperativista da Guiana (antiga Guiana Inglesa), ao Sudoeste com o Estado do Pará, ao Sul e Oeste com o Estado do Amazonas ${ }^{1}$ Com esse posicionamento geográfico, o Estado é considerado fronteira linguística, diante da incidência da língua portuguesa pelo lado brasileiro, das línguas de fronteira, como o espanhol e o inglês, pelo lado venezuelano e guianense respectivamente e pelas línguas indígenas pertencentes às etnias originárias do Caribe 
(Ye’kuana, Ingarikó, Katuenayama, Makuxi, Patamona, Sapará, Taurepang, Wai-Wai, Waimiri Atroari), dos Yanomami (Yanomami, Sanumá, Ninã, e Yanomae) e dos Aruak $(\text { Wapichana })^{2}$. Em sua formação populacional, há a presença de pessoas nascidas na região, de originários de outros Estados brasileiros, de indígenas e de estrangeiros. Vale salientar que o Estado conta, atualmente, com um número significativo de venezuelanos (indígenas e não indígenas), que migraram em função da crise político-social no seu país, além de guianenses, coreanos, haitianos, entre outros.

Nessa perspectiva, este artigo se baseia em uma pesquisa bibliográfica, a qual visa o debate sobre a formação continuada de professores, considerando as especificidades culturais, linguísticas e educacionais existentes em Roraima e faz parte das pesquisas das autoras na área de currículo, formação de professores e cultura.

Assim, dividimos este artigo em três momentos. Inicialmente, apontamos alguns conceitos importantes para fundamentar esta discussão, tais como multiculturalidade, interculturalidade, formação continuada de professores e o de currículo na perspectiva da diversidade cultural. Na sequência, apresentamos os aspectos interculturais presentes no ensino e na aprendizagem em língua portuguesa nas escolas brasileiras. Por conseguinte, finalizamos com a discussão sobre a realidade da formação continuada dos professores da educação básica do Estado de Roraima, um ambiente multiétnico e multicultural. Defendemos que este trabalho é essencial para ampliar o debate sobre a interculturalidade na formação continuada de professores.

\section{MULTICULTURALIDADE, INTERCULTURALIDADE E CURRÍCULO: DELINEANDO CONCEITOS}

$\mathrm{Na}$ contemporaneidade, o avanço da tecnologia em suas vertentes da mídia de informação, de comunicação e de divulgação do conhecimento, bem como as facilidades para o deslocamento dos povos e a diluição das fronteiras, tem impactado e acelerado o intercâmbio cultural. Condicionadas pela globalização, as culturas vão se transformando e "[...] fazendo cair por terra a noção de cultura coerente com um território e um povo" (WEISSMANN, 2018, p. 23). 
A sociedade contemporânea globalizada está marcada pela existência de grupos cada vez mais diversos e plurais e pela necessidade (nem sempre alcançada) da convivência harmônica entre eles, caracterizando-se pela multiculturalidade. Concordamos aqui com o conceito apresentado por Weissmann (2018) de que a multiculturalidade implica necessariamente um conjunto de culturas em constante contato, mas que não se misturam, nem se fundem, de forma que:

As diferenças ficam estanques e separadas em cada cultura, possibilitando pensar no que os antropólogos chamam a lógica do Um, que só tem uma verdade a seguir e uma forma de pensar o mundo. Aquela forma única não admite contraponto de ideias, nem ser discutida ou questionada. Baseia-se em uma lógica binária, na qual uma ideia é correta e outra é diferente e incorreta, só se complementando ideias similares e tentando se afastar aqueles conceitos que contrariam o pensamento predominante (WEISSMANN, 2018, p. 24).

Um dos obstáculos que se interpõe na busca da convivência pacífica e tolerante relaciona-se à visão de que, não raro, a diferença é associada à inferioridade e desigualdade, e o "outro" - que é diferente porque é diverso e plural - torna-se inferior e passa a representar uma ameaça aos padrões de ser e de viver (SILVA; BRANDIM, 2008).

Nesse contexto, algumas culturas consideram-se superiores, impondo uma visão de mundo às demais, a partir de padrões únicos de comportamentos e aceitações. Em nossa sociedade, com um forte ideário baseado na cultura dos grupos ocidentais brancos, que se autoproclamam mais capazes e melhores que os demais, os conflitos são cada vez mais comuns entre os grupos diversos, resultando em ações de exclusão, discriminação, preconceito, as quais, na maioria das vezes, geram conflitos e violência. ${ }^{3}$

Na perspectiva educacional, faz-se urgente considerar os aspectos da multiculturalidade presentes em nossas escolas. Diante do exposto, recorremos a Maclaren (1997) para referendar que a escola precisa alinhar-se ao que o autor chamou de "vertente crítica e de resistência", que trata a questão da diferença a partir da dimensão política, sendo resultado da história, da cultura, do poder e da ideologia; portanto, a diversidade só adquire significado, quando está inserida numa política de crítica comprometida com a justiça e a transformação social.

Para nós, essa perspectiva considera todo um movimento que se propõe a analisar as concepções e as experiências pedagógicas necessárias para o enfrentamento dos conflitos gerados “[...] em função das questões econômicas, políticas, e, mormente, étnico-culturais, na tentativa de combater discriminações e preconceitos, haja vista as dificuldades de indivíduos e 
grupos de acolher e conviver com a pluralidade e as diferenças culturais" (SILVA; BRANDIM, 2008).

Para prosseguir no debate sobre a realidade da diversidade presente em nossas escolas, consideramos fundamental o reconhecimento da multiculturalidade, avançando em direção ao conceito de interculturalidade. Para Weissmann (2018), a interculturalidade difere da multiculturalidade porque, em um mundo marcado pelas relações de interdependência suscitadas pela globalização e pelo esvaecimento das fronteiras ideológicas e culturais no processo de confrontação e entrelaçamentos, os grupos sociais diversos estabelecem relações e intercâmbios, nos quais a diferença pode gerar espaços de negociação, conflito e empréstimo recíproco, respeitando as disparidades:

Nas conexões, presta-se atenção às misturas e aos mal-entendidos que circulam nos grupos, para tentar compreender como cada grupo se apropria e reinterpreta os produtos simbólicos alheios. A interculturalidade nos permite tornar mais complexas as situações, dentre as quais as teorias da diferença têm que se articular com as concepções da interculturalidade, entendendo interação como desigual, conexão/desconexão, inclusão/exclusão. A política da diferença traz um equilíbrio interpretativo na interculturalidade (WEISSMANN, 2018, p. 26).

É necessário considerar, como faz a autora, a passagem do conceito de multiculturalidade para o da interculturalidade, reconhecendo a existência de "[...] culturas em conflito e em diálogo, ao mesmo tempo, não tentando obstruir as diferenças e sim fazer com que elas conversem e se entrelacem" (WEISSMANN, 2018, p. 27), para que possamos trabalhar com a diversidade presente em nosso sistema educacional.

Gusmão (2000) propõe que o primeiro passo a ser dado no trabalho com a diversidade na escola é o do reconhecimento das relações de alteridade, que devem nos constituir como sujeitos:

\begin{abstract}
Alteridade revela-se no fato de que o que eu sou e o outro é não se faz de modo linear e único, porém constitui um jogo de imagens múltiplo e diverso. Saber o que eu sou e o que o outro é depende de quem eu sou, do que acredito que sou, com quem vivo e por quê. Depende também das considerações que o outro tem sobre isso, a respeito de si mesmo, pois é nesse processo que cada um se faz pessoa e sujeito, membro de um grupo, de uma cultura e sociedade. Depende também do lugar a partir do qual nós nos olhamos. Trata-se de processos decorrentes de contextos culturais que nos formam e informam, deles resultando nossa compreensão de mundo e nossas práticas frente ao igual e ao diferente (GUSMÃO, 2000, p. 12).
\end{abstract}


No reconhecimento para trabalhar com diversidade, faz-se necessário também discutir qual a abordagem de currículo existente nas salas de aula. Na visão de Silva (1999), o currículo é uma questão de saber, poder e identidade, e não podemos conceber o currículo de forma ingênua e desvinculado de relações sociais de poder. Como o currículo é um documento de identidade e um lugar onde essas identidades são construídas, a diversidade considera os diferentes lugares e a trajetória percorrida pelos grupos sociais, conclui o autor (SILVA, 1999).

No currículo, ocorre o entrecruzamento das relações de poder e saber, de discurso e regulação, além da representação e domínio, no qual o poder e as identidades sociais estão intimamente implicados, pois ele corporifica as relações sociais. Assim, o currículo é elaborado entre as relações de saber e de poder, haja vista que os diferentes contextos históricos, sociais e culturais são permeados por relações de poder e de dominação, acompanhados de uma maneira tensa e, por vezes, ambígua ao lidar com a diversidade.

Com efeito, adotamos nesta análise o currículo como um campo entremeado de ideologia, cultura, de relações de poder e como uma construção social. Tais relações são condicionadas por questões profissionais e sociais postas na dinâmica social que, por meio dos movimentos de luta por igualdade de direitos sociais, políticos e culturais, reconfiguram as identidades e a cultura educacional.

Nessa seara, Feldmann (2009, p. 37) mostra que o currículo é uma construção "epistemológica e social do conhecimento, concretizado em espaços educativos e vivenciado em movimentos de tensões e lutas pela ocupação territorial dos saberes". O projeto político pedagógico, plano global de sistematização da escola, funciona como importante caminho para a construção da identidade da instituição e nele deve constar a intencionalidade do currículo, a qual vai direcionar toda a ação pedagógica, pois é na escola que esses saberes são concretizados. A autora complementa argumentando que o ato de ensinar é sempre um trabalho coletivo e a ação do professor, no âmbito escolar, é construída na relação com a comunidade escolar, por meio dos modelos ético-pedagógicos presentes em toda ação educativa, pelas finalidades do sistema escolar e do projeto político-pedagógico de cada instituição que direcionam todo o fazer pedagógico. O currículo tem uma ação direta e indireta na formação e no desenvolvimento do educando, visto que a ideologia, a cultura e o poder nele existentes, determinam o resultado educacional.

Logo, é fundamental que, ao proporcionarmos um olhar mais atento a essa discussão com toda a comunidade escolar, analisemos para compreender o que é, para que serve, a quem 
se destina, como se constrói e como se implementa o currículo, como argumentam os autores Moreira e Candau (2007, p. 6):

[...] levando em consideração que o processo educativo é complexo e fortemente marcado pelas variáveis pedagógicas e sociais, entendemos que esse não pode ser analisado fora de interação dialógica entre escola e vida, considerando o desenvolvimento humano, o conhecimento e a cultura. Há diversidade nas reflexões teóricas, porque há diversidade de projetos curriculares nos sistemas, nas escolas.

O currículo é uma construção cultural, portanto a qualidade da educação e do ensino está relacionada com o tipo de cultura que nele se desenvolve. O currículo é um espaço de produção de significados e atribuição de sentidos nos vários campos e atividades sociais e, como resultado, temos os ganhos educativos. Ele deve ser entendido como "[...] algo que adquire forma e significado educativo à medida que sofre uma série de processos de transformação dentro das atividades práticas que o têm mais diretamente por objeto" (GIMENO SACRISTÁN, 2000, p. 9).

Como o ensino não é uma atividade solitária, vazia, mas intencional e que requer uma interação sociocultural que vai além dos muros da escola, local por excelência produtor de subjetividades, é preciso clareza em alguns pressupostos com relação à sua individualização. Perez Gómez (2000) aponta que a crise na cultura crítica está influenciando o âmbito escolar, provocando entre os docentes a sensação de perplexidade ao comprovarem como se desarticulam os fundamentos que legitimam, ao menos teoricamente, sua prática. O autor levanta questões como: "Quais são os valores e conhecimentos da cultura crítica atual que merecem a pena trabalhar na escola? Como se identificam e quem os define?" (PÉREZ GÓMEZ, 2000, p. 57).

Nesse sentido, pensar em escola é pensar em uma instituição que proporciona a construção de cidadania, na qual as ações democráticas devem ser incentivadas, de forma a preparar os sujeitos para viverem e compreenderem o mundo. A escola contribui com a propagação do conhecimento, com a superação da ignorância e das superstições que escravizam o ser humano, com a preparação das pessoas para o exercício da cidadania, promovendo a diminuição das desigualdades, reflexo dos valores e contradições da cultura ao longo dos tempos. 
Ademais, a escola deve ser considerada um dos espaços de formação de uma pessoa que desejamos que seja autônoma, reflexiva e atuante, que possa transformar a sociedade em que vive. Nesse contexto, questionamos como o professor se prepara para a docência no âmbito das práticas didático-pedagógicas diante de uma escola marcada pela diversidade cultural, tal como a encontrada nas escolas da rede básica de ensino do Estado de Roraima. Nesse caso, o professor precisa saber como mediar as diferenças culturais e linguísticas existentes e, para tanto, necessita estar em constante formação, buscando refletir sobre sua práxis.

A resposta a esse questionamento está na formação continuada de professores, uma vez que esta é um continuum no desenvolvimento profissional do docente. Ela é um processo de aprendizagem, que requer que o professor compreenda as múltiplas relações dos diversos conhecimentos. Essas relações se dão tanto no campo epistemológico quanto nos âmbitos político, social, ideológico e filosófico da área específica de conhecimento que o docente deseja ampliar. Ademais, investir na formação é imprescindível, mas não deve ser qualquer formação. Esta deve ser pautada por uma concepção que supere a racionalidade técnica e que tenha uma proposta de formação para que os professores possam refletir sobre e como agir em seu trabalho pedagógico.

Falamos muito em "formação de professores", "formação continuada", "formação em serviço", "capacitação", "reciclagem"; mas pouco dizemos como essas formações devem ser e como estão sendo realizadas na prática. Pérez Gómez (2000) lembra que a produção do conhecimento válido e relevante é concebida como processo de construção de novos significados e representações, a partir do contraste das diferentes interpretações oferecidas pelos sujeitos participantes e a partir da situação de vida.

Para Feldmann (2009), as palavras e os sentidos encerram em si a dimensão da multidimensionalidade, da complexidade e da incompletude do saber e do ser professor, pois é preciso buscar os significados do que é ser professor como sujeito ao relacionar-se com os outros, exercitando a alteridade, elaborando a interpretação e a reinterpretação do mundo. Complementa a autora que os professores, "em suas ações educativas, lidam com a apropriação do conhecimento sistematizado, os significados, a cultura, a construção dos próprios saberes escolares e a dinâmica da própria organização do contexto escolar” (FELDMANN, 2009, p. 71).

Nesse sentido, é preciso que a escola e os professores percebam que é indispensável uma formação continuada dos profissionais docentes, na busca por compreender as variadas 
concepções, diversas abordagens e diferentes olhares que se fazem presentes no momento histórico e social. As discussões acerca da construção de identidade do professor perpassam pela formação da cidadania de seus sujeitos e pela concepção do professor como aquele que abraça saberes, valores, atitudes, que compartilha relações e, com o outro, elabora a interpretação e a reinterpretação do mundo. Assim, os beneficiários dessa ação não serão somente os professores, mas também a escola, a comunidade e os educandos.

Concordando com esse pensamento, propomos discutir as possibilidades de avançar para reconhecer a diversidade e trabalhar na perspectiva da interculturalidade na escola, tomando como foco o ensino e a aprendizagem da e na língua portuguesa no ambiente intercultural presente nas escolas do Estado de Roraima.

\section{OS ASPECTOS INTERCULTURAIS PRESENTES NO ENSINO E NA APRENDIZAGEM EM LÍNGUA PORTUGUESA}

A linguagem reflete tanto as características individuais de uma pessoa como as crenças e práticas de sua comunidade, estabelecendo uma estreita relação entre linguagem e identidade. Podemos afirmar que as línguas são sistemas governados por regras, compostos por sinais empregados por determinada comunidade que dão significados a estes, e que geram a comunicação entre seus membros, os quais conhecem suas regras e os elementos que formam o sistema da referida língua e, mediante esses recursos, criam uma quantidade de mensagens (AMBERG; VAUSE, 2008).

Como o sistema linguístico no Brasil é representado oficialmente pela língua portuguesa, podemos afirmar que fomos alfabetizados e somos falantes da língua portuguesa. É preciso lembrar que em um país como o Brasil, com a diversidade cultural existente, tal premissa não é unânime, uma vez que alguns autores defendem que essa diversidade deve ser reconhecida na constituição de uma língua nacional brasileira (ORLANDI, 2005; COSTA, 2012).

A sociedade brasileira utiliza e sistematiza o termo língua portuguesa e a escola assume a tarefa de ensiná-la, estabelecendo também as práticas sociais de seu uso. Destacamos que a forma como serão determinados esse ensino e a aprendizagem está fundamentada sobre uma 
concepção de língua. Para Patriota e Pereira (2018), a língua pode ser concebida de três modos: como expressão de pensamento, como instrumento de comunicação e como maneira de interação. Os autores destacam que:

Na primeira concepção, a língua é relacionada ao funcionamento da mente humana, a qual está enraizada na Gramática Tradicional. Na segunda concepção, a língua é considerada como um código pré-estabelecido, que é dominado por, pelo menos, dois falantes e que, portanto, possibilita os atos de comunicação entre eles. Na última concepção, a língua é compreendida como um meio de realizar ações sobre o interlocutor, concebendo-a, assim, como um lugar de interação, o qual possibilita a troca mútua dos conhecimentos e experiências entre os falantes (PATRIOTA; PEREIRA, 2018, p. 290).

Sendo a língua portuguesa marcada pela multiplicidade, depreende-se que essa característica esteja presente e seja considerada em seu processo de ensino e aprendizagem. Contudo, isso não acontece. No mais das vezes, na escola, a abordagem atribuída ao ensino da língua portuguesa e ao uso da língua portuguesa para ensinar os demais conteúdos está associada ao ensino da gramática normativa, que "[...] privilegia veementemente o estudo da norma-padrão [...] excluindo as demais habilidades e competências sociocomunicativas dos alunos, inseridas nestas as variedades linguísticas oriundas da realidade social de cada um" (PATRIOTA; PEREIRA, 2018, p. 291). Nesse sentido, mantém-se a concepção de homogeneidade da língua portuguesa, o que implica estabelecer que existe uma língua-padrão, correta, e aquela que não acompanhar as regras não fará parte dessa normativa e segue sendo considerada errada, desafiando a dinamicidade linguística presente nas escolas brasileiras.

Esse processo de homogeneização ocorre quando os quatro eixos (oralidade, leitura, produção textual, análise linguística) são trabalhados no processo de ensino e aprendizagem da e com a língua (independentemente da língua que está sendo ensinada). A escola precisa transcender o ensino tradicional para uma prática natural na qual ocorram situações reais e significativas de uso da linguagem. A função da escola é a formação de um aluno, que interaja socialmente de maneira participativa, ou seja, saiba compreender o que lê e ouve (atividades de percepção), além de saber expressar-se tanto por escrito quanto oralmente (atividade de produção) nas mais diversas formas de interação social.

A Base Nacional Comum Curricular aponta como uma das competências a ser desenvolvida ao longo da educação básica:

Utilizar diferentes linguagens - verbal (oral ou visual-motora, como Libras, e escrita), corporal, visual, sonora e digital -, bem como conhecimentos das 
linguagens artística, matemática e científica, para se expressar e partilhar informações, experiências, ideias e sentimentos em diferentes contextos e produzir sentidos que levem ao entendimento mútuo (BRASIL, 2018, p. 8).

Esse entendimento pressupõe que toda linguagem deve ter um caráter de expressão com significância para todos os que interagem no ambiente escolar, e essa orientação deve permear os currículos das escolas.

O contato com a diversidade cultural e linguística nessa sociedade globalizada é intensificado por meio dos inúmeros sistemas de comunicação e tecnologias. O ensino e a aprendizagem em uma língua assumem papel importante, pois é preciso desenvolver e ampliar a competência comunicativa dos aprendizes. Ressaltamos que uma língua, independentemente de ser língua materna ou estrangeira ${ }^{4}$, é constituída de significados culturais que devem ser adquiridos pelos que vão aprendê-la. Esse aspecto da linguagem é corroborado por Amberg e Vause (2008, p. 1), quando afirmam, em uma perspectiva eminentemente cultural, que, "para um estranho aprender a língua de uma comunidade, ele deve aprender quais sinais são significativos e quais não são". Assim, para estar integrado em uma comunidade como leitor, escritor, falante e ouvinte, o sujeito precisa do suporte da linguagem-padrão, a que vai ser utilizada em toda a sua formação escolar.

Em um país continental como o Brasil, mesmo que a língua-padrão seja a língua portuguesa, ela sofre alterações de acordo com as regiões e épocas. Por exemplo, o livro $A$ Moreninha, de Joaquim Manuel de Macedo, publicado originalmente em 1844, marco do início da ficção do romantismo brasileiro, se fosse editado hoje com a linguagem daquela época seria difícil a compreensão de seu teor por um leitor. Nos últimos 176 anos, a língua portuguesa sofreu modificações, pois é viva e dinâmica. O mesmo ocorre com a cultura, uma vez que os modos de comportamento são muito diferenciados daqueles do século XIX. À medida que a linguagem foi se adaptando às mudanças culturais da sociedade brasileira, sejam elas determinadas geográfica ou historicamente, ela foi adquirindo um caráter de multiplicidade em oposição direta à perspectiva de uma unicidade-padrão. A língua portuguesa falada, escrita e ouvida no Brasil é carregada de sotaques, polissemias, significâncias e significados que estão presentes no dia a dia das escolas brasileiras.

A linguagem é uma área que traz para a ação educativa um forte componente multicultural, que precisa ser reconhecido para ser trabalhado nas salas de aula. Contudo, 
admitimos as dificuldades de estabelecer a diversidade cultural da linguagem quando de seu uso no ensino e aprendizagem dos conteúdos curriculares escolares, uma vez que, embora o Brasil seja um país multicultural, as escolas e seus currículos continuam presos a uma prática monocultural (MORAIS; VELANGA, 2017).

Nessa perspectiva, colocamos a linguagem como um dos mais poderosos vetores de inclusão e, na mesma proporção, de exclusão. Lembramos que vivemos em uma sociedade em que a internacionalização do capital propicia a produção, a distribuição e o consumo de bens de forma padronizada em todo o mundo, o que assegura o caráter opressivo da globalização com relação às identidades culturais diversas, sobretudo quando se leva em conta que globalizar pode significar homogeneizar, diluindo identidades e apagando as marcas das culturas ditas inferiores (FLEURI, 2003).

Reverberando no campo educacional, a globalização tem um impacto avassalador na sociedade em que vivemos, uma vez que provoca "[...] mudanças nas concepções de conhecimento, na construção e na integração de saberes, o que intensificou a competição produzindo um movimento de padronização educacional” (MARQUES et al., 2018, p. 39). A linguagem tem um caráter ambíguo, em que tanto pode contribuir para esse processo de padronização quanto para o de encaminhar a negação e a ruptura de padrões nos diferentes grupos sociais.

De acordo com Moreira (2004 apud MORAIS; VELANGA, 2017), as políticas educativas ainda são permeadas pela ideia de uma cultura homogênea, em que a educação é destinada a conformar alunos/alunas à função de bons cidadãos/cidadãs, que cumprem deveres, partilham uma mesma identidade nacional e se mostram leais ao Estado-Nação. Para Morais e Velanga (2017), tais políticas induzem à construção de uma escola que se coloca completamente para a promoção da homogeneidade e consequente negação da diversidade:

Uma escola que, embora tenha se expandido por meio de um processo de universalização (democratização) do ensino, contribui ainda para a manutenção da exclusão por dentro de seus muros, por meio de metodologias descontextualizadas, programações lineares, temporalidade inflexível e categorias como de sucesso e insucesso, normalidade e anormalidade, atraso e fracasso escolar, na qual tende a excluir aqueles que não acompanham a padronização que as propostas educacionais impõem (MORAIS; VELANGA, 2017, p. 302).

Na manutenção dessa escola excludente, com suas metodologias descontextualizadas, a língua portuguesa tem um papel preponderante, uma vez que ela é usada de forma padronizada 
com todas as suas normas no ensino dos conteúdos curriculares. Nesse pensar, para que o aluno aprenda os conteúdos curriculares diversos, ele precisa "dominar" a língua-padrão, nesse caso, a língua portuguesa.

É preciso fugir de tal determinação, porque no Brasil existem diversas comunidades que utilizam linguagens diferentes da língua portuguesa, por exemplo, em grupos de imigrantes e nas comunidades indígenas. Mas não só isso. Em nossa pesquisa, deparamo-nos com comunidades da fronteira roraimense onde são falados o inglês/português (Guiana) ou o espanhol/português (Venezuela), além de comunidades indígenas, onde são falados uma ou duas línguas indígenas, o português, além do inglês ou do espanhol.

Nesse cenário, o ensino dos conteúdos das diversas áreas de conhecimento encontra forte relação com a cultura e a valorização de identidade, na busca da formação cidadã autônoma. Concordamos com Candau (2000, p. 14) quando diz que as escolas precisam ser reinventadas, pois "estão cada vez mais desafiadas a enfrentar os problemas decorrentes das diferenças e pluralidade cultural, étnica, social, religiosa etc., dos seus sujeitos e atores”.

Portanto, propomo-nos a refletir sobre esse caldeirão de diversidade cultural, essencialmente multiétnico, tomando como foco a formação continuada de professores no Estado de Roraima, tendo em vista que sua localização geográfica de tríplice fronteira pressupõe também o estabelecimento de uma fronteira linguística, pois o Estado conta com a presença considerável de pessoas de outros países (Guianas e Venezuela, principalmente), que se deslocam em busca de sobrevivência e de diversas comunidades indígenas.

\section{A (NECESSÁRIA) FORMAÇÃO CONTINUAdA DOS PROFESSORES PARA TRABALHAR COM A INTERCULTURALIDADE}

Vivemos em uma era globalizada, com tecnologias que, para Silva (2016), oportunizam ao homem o conhecimento das "diversidades culturais, linguísticas e étnicas do mundo" (SILVA, 2016, p. 245). É uma era em que a informação é muito veloz, o outro lado do mundo está logo ali, para conhecermos como as pessoas vivem e sabermos o que acontece. Entretanto, Silva (2016, p. 245) questiona: “[...] as pessoas estão mais próximas? Realmente há conhecimento ou reconhecimento das diversas culturas e das diversas línguas? Realmente, com 
a distância reduzindo-se a um click, as diferenças étnico-raciais são respeitadas e vistas como algo natural?". Essas indagações são pertinentes quando pensamos em nosso cotidiano e percebemos que o outro, antes distante geograficamente, hoje está "dentro de nossa casa" por meio dos canais de comunicação. Essa "proximidade" nos faz ver o outro como ele realmente se apresenta ou de acordo com nossas convicções?

Se pensarmos no campo educacional, em nossas salas de aula, o outro não está longe, mas perto geograficamente. E como vemos o outro? Essa questão provoca diversas respostas, e, para que o professor as encontre, ele deve ser também um pesquisador de sua práxis e estar em constante processo de formação.

Esse processo de formação continuada encontra eco em Richter (2005, p. 7), quando aponta que as "boas práticas docentes no ensino de línguas exigem que se pense em diversas variáveis didáticas ao planejar, implementar e aperfeiçoar cursos”. Isso porque, para o autor, ao ensinar, o professor deve partir de uma análise de necessidades, de acordo com o perfil dos alunos, a fim de permitir estabelecer o que os estudantes precisam aprender, bem como o que esperam aprender. O autor considera que, ao ensinar uma língua, ou em uma língua, há uma diversidade de aspectos "que se entrelaçam de maneira complexa: funções, tópicos, estratégias comunicativas, gêneros, questões culturais, entre outros” (RICHTER, 2005, p. 7).

Por essa razão, a perspectiva do professor de ver o outro é a de considerar o aluno como um sujeito com diferenças culturais, linguísticas, sociais, étnicas, entre outras, a quem precisa ser proporcionada a formação de um cidadão integral (crítico, reflexivo, participativo e autônomo), de modo que ele possa ser protagonista de sua vida pessoal e profissional. Logo, o professor precisa trabalhar sua sala para que seus alunos também vejam o outro como um colega, companheiro de estudo, que tem diferenças, mas que também tem direito à voz. Portanto, o ensino e a aprendizagem em uma sala de aula devem considerar as peculiaridades locais, tanto culturais quanto linguísticas, de seus falantes.

Nessa seara, o ensino da e na língua encontra forte relação com a cultura e a valorização de identidade na busca da formação cidadã autônoma. Para Signorini (1998, p. 31), temos constantemente contato com uma comunicação linguística multicultural e diferente entre os grupos sociais, visto que:

A cultura é o conjunto de tradições, estilos de vida, formas de pensar, sentir e atuar de um povo, a cultura se diferencia entre os grupos sociais e ao mesmo 
tempo pode se unir a estes grupos, vinculados por meio da interação entre os processos sociais, o ensino e hábitos de idioma.

Não existe uma cultura superior ou inferior à outra, mas possibilidades de coexistirem harmonicamente. Essa harmonia está relacionada ao respeito pelo outro e suas diferenças. Vale salientar que a maioria de nossas salas de aula é um ambiente multicultural e multiétnico e, por isso, precisamos refletir sobre o ensino e a aprendizagem da e na língua portuguesa veiculada nas escolas. Essa diversidade de culturas proporciona a formação do respeito às diferenças e o ensino em uma perspectiva intercultural.

É nessa perspectiva de estudo da interculturalidade em sala de aula, e atendendo à demanda local sobre essa multiculturalidade, que a formação continuada dos profissionais em educação de Roraima ocorre por meio do Centro de Formação dos Profissionais da Educação de Roraima (CEFORR), órgão pertencente à Secretaria Estadual de Educação e Desporto (SEED/RR). O CEFORR tem ofertado cursos que possibilitam a reflexão do professor sobre o ensino e aprendizagem em um contexto de fronteira linguística. Em uma de suas propostas de formação continuada, o CEFORR $(2019$, p. 4) defende que ela aconteça a partir de:

[...] reflexões críticas e qualificação teórico-metodológica a fim de fomentar práticas pedagógicas que favoreçam o diálogo intercultural e interfronteiriço entre as escolas de Roraima, pautadas na realidade sociocultural da pluralidade étnico-racial e de gênero, no sentido de garantir o respeito aos direitos fundamentais relativos à democracia, identidade, valorização e respeito às diferenças 5 .

Tais ações trazem como uma das reflexões colocadas em pauta a interculturalidade em sala de aula no ensino e na aprendizagem da e na língua portuguesa, porquanto no Estado de Roraima encontramos alunos brasileiros roraimenses e/ou descendentes de brasileiros das mais diversas regiões do País, alunos venezuelanos, alunos guianenses, bem como alunos indígenas brasileiros, alunos indígenas venezuelanos, alunos indígenas guianenses, entre outras nacionalidades, em uma mesma sala de aula.

Nesse contexto, o professor precisa refletir que esse aluno se depara com uma sala de aula em que o conhecimento é tratado em uma língua que para ele era estrangeira e agora passa a ser sua segunda língua, a qual ele necessita conhecer para interagir socialmente e para aprender os conteúdos curriculares. Além disso, esse aluno está em um ambiente em que a cultura é, em muitas situações, diferente da sua. Vale salientar que o ensino na e da língua não 
é responsabilidade apenas do professor de língua portuguesa, mas de todo o corpo docente da escola, pois estamos falando do desenvolvimento de um cidadão.

Ao observarmos a realidade intercultural roraimense, percebemos que esse fato não diz respeito apenas aos imigrantes, mas também aos indígenas brasileiros que têm seu direito assegurado pela Constituição Federal, de ensino da língua materna em suas comunidades. Muitas comunidades indígenas são mistas, compostas de mais de uma etnia, além da presença de não índios. Visto que o professor atua em salas multiétnicas e multiculturais, convivendo com alunos de etnias indígenas diferentes, alunos brasileiros e alunos estrangeiros, eis as questões que devem ser colocadas por ele: Em qual língua ensinar? Qual cultura privilegiar? Tal fato nos faz pensar que o professor, ao trabalhar o conhecimento de sua área, deve estar preparado, atento e aberto ao reconhecimento das diferenças culturais e linguísticas de seus alunos. Isso é fundamental para que todos os alunos tenham condições de compreender, desenvolver suas competências e relacionar-se socialmente, sem perder sua identidade. Para que isso ocorra, uma cuidadosa formação continuada deve ser pensada, considerando o aspecto intercultural das turmas de alunos e disponibilizada para os professores para que eles possam inicialmente identificar qual diversidade linguística e quais culturas existem em sua sala de aula, para acolher, respeitar e realizar seu trabalho docente na perspectiva da inclusão cultural.

\section{CONCLUSÃO}

Discutimos aqui como as diversidades linguísticas impactam os processos de ensino e aprendizagem, por isso a escola não pode continuar desempenhando o papel de lócus da homogeneização, quando a sociedade é diversa e plural. Nesse sentido, faz-se necessário estabelecer de vez a existência da diversidade cultural e linguística presentes em sala de aula, para que a escola cumpra sua função de formação de um cidadão que interaja socialmente e de forma participativa.

Compreendemos a enorme dificuldade dos professores no enfrentamento da realidade multiétnica e, portanto, carregada de diversidade cultural, presente nas escolas roraimenses, mas destacamos que esse enfrentamento é urgente e necessário e deve ser feito não somente pelos docentes de língua portuguesa, mas por todo o corpo docente responsável pelo ensino dos vários conteúdos curriculares. 
E mais uma vez será no trabalho docente que as rupturas começarão a se estabelecer, porque são os professores que lidam de perto com a realidade heterogênea das salas de aula. Eles precisarão reconhecer a diversidade para avançar nas ações de desconstrução da homogeneização e no encaminhamento das ações, que viabilizem o ensino e a aprendizagem nessa realidade. O professor, pesquisador de sua práxis, é quem poderá direcionar sua ação pedagógica e determinar o que, como, por que e para quem ensinar, partindo de uma análise das necessidades de seus educandos. É por meio dessa reflexão de seu fazer pedagógico sobre o ensino e a aprendizagem que ele construirá um percurso educativo de acordo com a realidade política, social e cultural de sua comunidade.

A formação continuada, na perspectiva da interculturalidade, deve ser o apoio que possibilitará ao professor compreender como a diversidade cultural e a linguística devem ser trabalhadas em sala de aula, tendo em vista a questão multiétnica existente nas escolas de Roraima. Esse processo formativo deverá permear uma qualificação teórico-metodológica que favoreça o diálogo intercultural pautado pela realidade sociocultural, garantindo o respeito e o direito à diversidade. A formação continuada do professor, nessa perspectiva, independentemente da área em que ele trabalha, poderá propiciar um olhar mais atento a essa diversidade, pois o reconhecimento das diferenças estimula as indagações, as propostas e os procedimentos pedagógicos que vão determinar suas práticas docentes.

\section{REFERÊNCIAS}

AMBERG, Julie S.; VAUSE Deborah J. American English: history, structure, and usage. New York: Cambridge University Press, 2009.

BRASIL. Ministério da Educação. Secretaria de Educação Básica. Base Nacional Comum Curricular. Brasília, DF, 2018.

CANDAU, Vera Maria (Org.). Reinventar a escola. Petrópolis: Vozes, 2000.

COSTA, Maria Iraci Sousa. A constituição de um imaginário de língua homogênea na/pela gramática. Revista Conexão Letras, v. 7, n. 8. 2012. Disponível em:

https://seer.ufrgs.br/conexaoletras/article/view/55449. Acesso em: 22 abr. 2020.

DAMASCENO, Rafaela. Língua estrangeira, materna, segunda língua, qual o significado? Disponível em: https://cacs.org.br/linguas/lingua-estrangeira/. Acesso em: 20 jul. 2017. 
FELDMANN, Marina Graziela. Formação de professores e escola na contemporaneidade. São Paulo: Editora Senac, 2009.

FLEURI, Reinaldo Matias. Multiculturalismo e interculturalismo nos processos educacionais. In: LINHARES, Celia Frazão et al. Ensinar e aprender: sujeitos, saberes e pesquisa. ENDIPE. Rio de Janeiro: DP\&A, 2003. p. 67-81.

GIMENO SACRISTÁN, José. O currículo: uma reflexão sobre a prática. Porto Alegre: Artmed, 2000.

GUSMÃO, Neusa Maria Mendes. Desafios da diversidade na escola. Revista Mediações, Londrina, v. 5, n. 2, p. 9-28, jul./dez. 2000.

McLAREN, Peter. Multiculturalismo crítico. São Paulo: Cortez, 1997.

MARQUES, Eveline Ignácio da Silva; SILVA, Jozimeire Angelica Stocco de Camargo Neves da; SPOTTI, Carmem Véra Nunes. A cultura educacional que permeia o currículo da educação básica do século XXI. In: FELDMANN, Marina G. (Org.). Formação de professores: currículo, contexto e culturas. Curitiba: Apris, 2018. p. 39-49.

MORAIS, Lerkiane Miranda de; VELANGA, Carmen Tereza. Diversidade cultural na escola: desafios para a prática docente. RECH- Revista Ensino de Ciências e Humanidades - Cidadania, Diversidade e Bem Estar, ano 1, v. I, n. 1, p. 299-321, jul./dez. 2017. Disponível em: https://www.periodicos.ufam.edu.br/index.php/rech/article/view/4744. Acesso em: 10 maio 2020.

MOREIRA, Antônio Flávio Barbosa; CANDAU, Vera Maria. Indagações sobre currículo: currículo, conhecimento e cultura. Brasília: Ministério da Educação, Secretaria de Educação Básica, 2007. Disponível em:

http://portal.mec.gov.br/seb/arquivos/pdf/Ensfund/indag3.pdf. Acesso em: 8 maio 2020.

ORLANDI, Eni Puccineli. A língua brasileira. Ciência e Cultura, São Paulo, v. 57, n. 2, p. 29-30, jun. 2005. Disponível em:

http://cienciaecultura.bvs.br/scielo.php?script=sci_arttext\&pid=S0009-67252005000200016. Acesso em: 15 jun. 2020.

PATRIOTA, Luciene Maria; PEREIRA, Paulo Ricardo Ferreira. O lugar da variação linguística na Base Nacional Comum Curricular (BNCC). Revista Letras Raras, v. 7, n. 2, p. 289-307, 2018. Disponível em:

http://revistas.ufcg.edu.br/ch/index.php/RLR/article/view/1066. Acesso em: 30 maio 2020.

PÉREZ GÓMEZ, Angel I. La cultura escolar en la sociedade neoliberal. Madrid: Morata, 2000. 
RICHTER, Marcos Gustavo. O material didático no ensino de línguas. Linguagens e Cidadania, v. 7, n. 2, jul./dez. 2005. Disponível em: https://periodicos.ufsm.br/LeC/article/view/28543/16099. Acesso em: 3 jun. 2020.

SIGNORINI, Inês. Língua(gem) e identidade: elementos para uma discussão no campo aplicado. Campinas: Mercado de Letras; FAPESP, 1998.

SILVA Maria José Albuquerque da; BRANDIM, Maria Rejane Lima. Multiculturalismo e educação: em defesa da diversidade cultural. Revista Diversa, Parnaíba, Edufpi, ano 1, n. 1, p. 51-65, jan./jun. 2008.

SILVA, Paula de Almeida. Cultura e interculturalidade no ensino de línguas: descobrindo caminhos possíveis. Diálogo das Letras, Pau dos Ferros, v. 5, n. 2, p. 245-265, jul./dez. 2016.

SILVA, Tomaz Tadeu da. Documentos de identidade: uma introdução às teorias do currículo. Belo Horizonte: Autêntica, 1999.

SPINASSÉ, Karen Pupp. Os conceitos de língua materna, segunda língua e língua estrangeira e os falantes de línguas alóctones minoritárias no Sul do Brasil. Revista Contingentia, v. 1, nov. 2006. p.1-8.

WEISSMANN, Lisette. Multiculturalidade, transculturalidade, interculturalidade.

Construção Psicopedagógica, São Paulo, v. 26, n. 27, p. 21-36, 2018. Disponível em: http://pepsic.bvsalud.org/scielo.php?script=sci_arttext\&pid=S141569542018000100004\&lng $=\mathrm{pt \& nrm=iso}$. Acesso em: 20 jun. 2020.

\section{NOTAS}

${ }^{1}$ Disponível em: https://mapas.ibge.gov.br/r. Acesso em: 20 maio 2020.

2 Disponível em: http://pib.socioambiental.org/pt/c/quadro-geral. Acesso em: 20 maio 2020.

${ }^{3}$ A recente onda de protestos que se espalhou pelo mundo contra a violência racial (naturalizada na sociedade a partir de agressões e discriminações diversas contra pessoas negras), ecoando o movimento "Vidas negras importam", é um exemplo claro de que em uma sociedade plural não se pode mais tolerar qualquer forma de racismo ou discriminação.

${ }^{4}$ A língua materna (ou idioma materno ou língua nativa ou primeira língua) é o primeiro idioma aprendido por um indivíduo e é a língua falada no país em que ele nasceu e/ou aprendeu a falar. A língua estrangeira (ou língua segunda) é a língua de outro país, que não é o seu de origem, e que o indivíduo aprende em circunstâncias diversas (DAMASCENO, 2017).

${ }^{5}$ Nota de aula do Curso "Proposta de formação continuada para o contexto de imigração emergencial: interfaces e abrangências em fronteiras, realizado pelo CEFORR com apoio do UNICEF no ano de 2019.

Recebido em: 30/06/2020

Aprovado em: 27/08/2020

Revista e-Curriculum, São Paulo, , v. 18, n.3, p. 1178-1196 jul./set. 2020 